Paper published as:

"Paillex A, Reichert P, Lorenz AW, Schuwirth N. Mechanistic modeling for predicting the effects of restoration, invasion and pollution on benthic invertebrate communities in rivers. Freshwater Biol. 2017; 62:1083-1093. https://doi.org/10.1111/fwb.12927"

\title{
Mechanistic modeling for predicting the effects of restoration, invasion and pollution on benthic invertebrate communities in rivers
}

Running Head: Mechanistic modeling for rivers

Amael Paillex * ${ }^{*}$ Peter Reichert ${ }^{*}$, Armin W. Lorenz ${ }^{\dagger}$, Nele Schuwirth *

\section{Affiliations:}

*Eawag: Swiss Federal Institute of Aquatic Science and Technology, Department of Systems Analysis, Integrated Assessment and Modelling, Überlandstrasse 133, CH-8600 Dübendorf, Switzerland

${ }^{\dagger}$ University of Duisburg-Essen, Faculty of Biology, Department of Aquatic Ecology, Universitätsstr. 5, D-45141 Essen, Germany

Correspondence: Amael Paillex, System Analysis, Integrated Assessment and Modelling, Eawag, Swiss Federal Institute of Aquatic Science and Technology, Überlandstrasse 133, P.O. Box 611, 8600 Dübendorf, Switzerland, e-mail: amael.paillex@swissonline.ch; Nele Schuwirth, email: nele.schuwirth@eawag.ch 


\section{Summary}

1. Habitat destruction, biological invasions and water quality deterioration are serious threats to native communities and can lead to modifications in community composition and structure, and in ecosystem function.

2. To predict the consequences of river restoration, biological invasions and water quality change on the taxonomic composition of macroinvertebrate communities in rivers, we extended the mechanistic model Streambugs, which describes growth, respiration and death of interacting taxa under given environmental conditions.

3. The model parameterized with prior knowledge on macroinvertebrate traits had already a reasonable explanatory power for data from restored and unrestored sites in two Swiss rivers. As expected, the explanatory power could even be increased by learning from observations through Bayesian inference. The predictive application of the model to changes in water quality and invasions by alien species indicated the importance of integrative planning of management measures: while invasive species are predicted to be able to colonize restored and unrestored sites and replace native species, both invasion of alien and subsequent exclusion of native taxa is predicted to be reduced when water quality improves.

4. The unavoidable simplification in the mathematical description of complex interactions in the macroinvertebrate community results in predictions that are uncertain. Our modelling techniques make the best attempt to quantify this uncertainty. Despite the uncertainty that always calls for more research, this study makes a considerable step towards improving our understanding of community structure and supporting river management through

mechanistic, predictive modelling of macroinvertebrate communities in rivers under changing environmental conditions.

Keywords: food-web theory, metabolic theory, mechanistic model, uncertainty, Bayesian inference.

\section{Introduction}

Among all types of ecosystems, freshwater ecosystems are particularly highly threatened by habitat degradation, biological invasion, pollution and future climate change (Sala et al., 2000; Tockner \& Stanford, 2002; Vorosmarty et al., 2010). Scenarios for the next century indicate that biodiversity will continue to decline (Pereira et al., 2010), with important cascading effects on ecosystem functioning and services (Dirzo et al., 2014). To prevent further decline of aquatic biodiversity and protect ecosystem functioning and services, restoration has become a serious priority worldwide. Despite these efforts, there are still considerable uncertainties about the consequences of the implementation of restoration measures (Bernhardt et al., 2005; Moreno-Mateos et al., 2012).

Forecasting and assessing the effect of restoration measures on biodiversity has thus become increasingly important (Lamouroux et al., 2015). This requires a model of the expected response of the community to the implemented restoration measures. Such a model can be (i) a mental model of an expert who extracts experience from case studies and mechanistic knowledge (Townsend \& Hildrew, 1994; Jones et al., 2012; Floury et al., 2013; Arce et al., 2014; Hering et al., 2015); (ii) a statistical model based on analyses of field data from sites with different environmental conditions and/or before-after observations of restored sites regarding species distributions (e.g. Domisch et al., 2015), or community descriptors (Jahnig 
et al., 2010; Leps et al., 2015; Paillex et al., 2015); or (iii) a mechanistic model that combines prior knowledge about ecosystem structure and functioning (e.g. regional species pools, species traits, stoichiometric and metabolic relationships) with empirical data (as done in this study). All three approaches provide insights into the potential response of communities to changes in external drivers. However, the third approach makes the attempt to synthesize mechanistic understanding in the most explicit way by fitting parameters of mechanistically formulated processes. Still, also in this approach, there is no guarantee that the mechanistic "explanation" by the model is correct. This problem is exacerbated by the fact that in most cases, models at the taxonomic level will be overparameterized (i.e. excessive number of parameters leads to identifiability problems during calibration and to poor predictive capabilities of a model) and will contain non-identifiable parameters. Therefore, such a modelling approach needs several iterations through experimental, observational, and modelling studies to improve and confirm the model. In a single study, just one of these steps can be done.

Among freshwater organisms, aquatic macroinvertebrates are an important component of biodiversity in river ecosystems, and they play an essential role for many ecosystem functions. Their coexistence at a site is dictated by the habitat types, the availability of food resources, the interactions between the species, the quality of the water, and the possibility of colonization (Merritt \& Cummins, 1996; Poff, 1997). River restoration will primarily improve the habitats by improving the morphology of the river. The aim is to recreate environments similar to natural habitats that are available for native communities. The colonization process by these native communities can take considerable time. The short-term disruption of the restoration process itself can lead to a partial extinction of the communities, and it will create empty niches which might possibly be colonized by invasive species (Strayer, 2010; Paillex et al., 2015).

In the context of two restoration projects in Switzerland (Fig. 1), we extended and applied the mechanistic model Streambugs for aquatic macroinvertebrates (Schuwirth \& Reichert, 2013; Schuwirth, Dietzel \& Reichert, 2016). The model combines food-web theory, the metabolic theory of ecology (Brown et al., 2004), and ecological stoichiometry (Andersen, Elser \& Hessen, 2004; Reichert \& Schuwirth, 2010) with the use of functional traits (Liess \& von der Ohe, 2005; Schmidt-Kloiber \& Hering, 2015) to predict the coexistence of invertebrate taxa in streams. We addressed four goals: 1) to test the ability of a mechanistic model to predict consequences of restoration on invertebrate communities, 2) to quantify model uncertainty and update prior knowledge about parameters with Bayesian inference, 3) to simulate the effect of invasive species arriving in the system on biodiversity, and 4) to simulate the effect of improving the water quality on the occurrence of native and invasive taxa. We hypothesized that morphological and physical changes induced by restoration should lead to predictable biodiversity changes (Townsend \& Hildrew, 1994; Hering et al., 2015), that restoration creates empty niches favorable for invasive species (Paillex et al., 2015), and that increasing water quality would promote the re-establishment of species sensitive to pollution. 


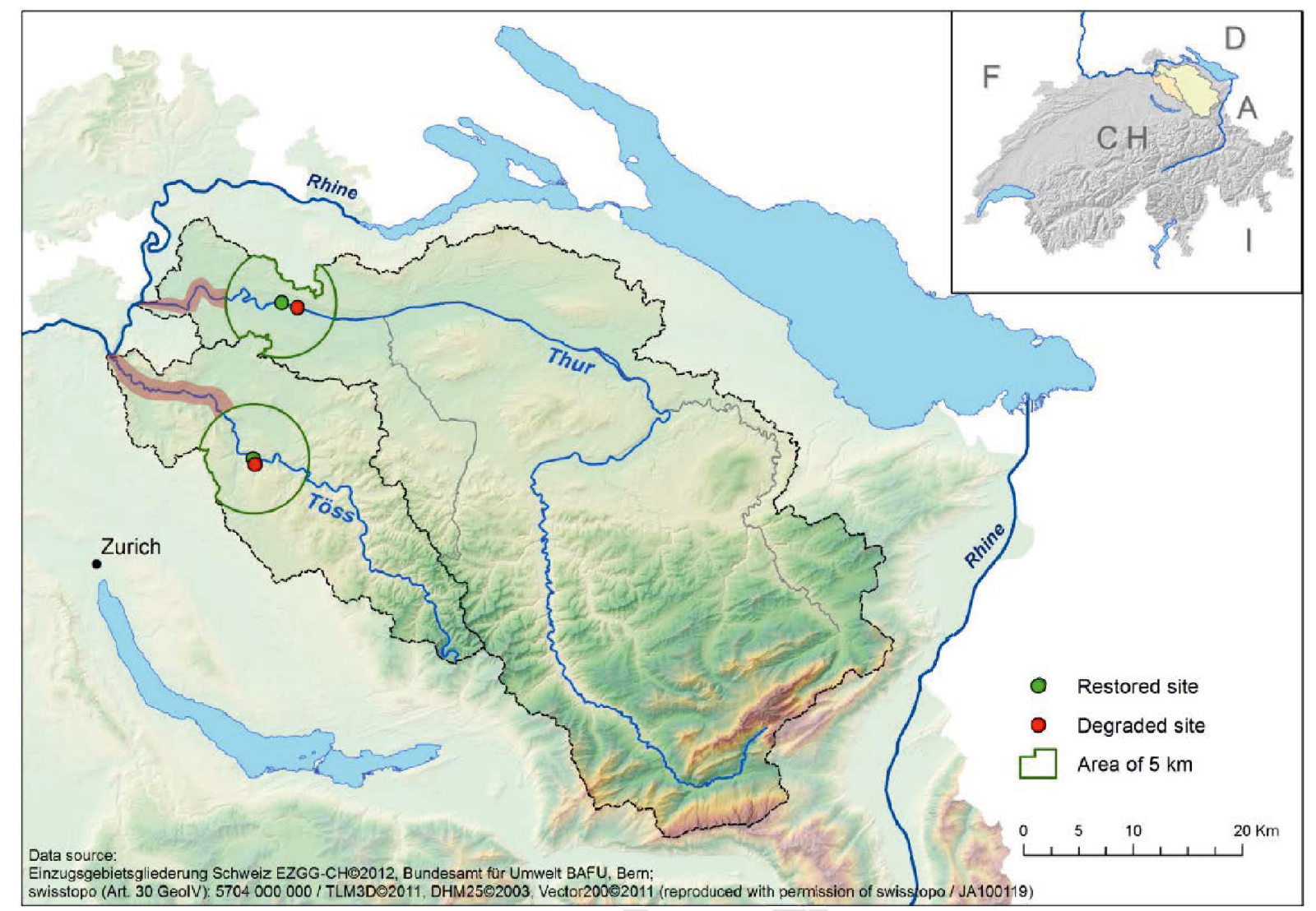

Fig. 1 Study sites along two rivers in the North-East of Switzerland. Downstream dots represent the positions of the restored sites, and the upstream dots indicate the positions of the unrestored sites. Circles delimitate the areas of sources for colonization, and correspond to an area within a $5 \mathrm{~km}$ distance from the restored sites. The catchments of the Thur and Töss Rivers have areas of $1605 \mathrm{~km}^{2}$ and $188 \mathrm{~km}^{2}$, respectively. Both rivers are tributaries of the Rhine River, flowing to the North of Europe. The pathways of colonization for alien species coming from the Rhine River are highlighted from the connection of the River to the Rhine toward the areas of sources for colonization.

\section{Materials and Methods}

\section{The Model}

The model Streambugs is a food web model that describes the growth, respiration and death of invertebrates and periphyton based on environmental conditions and the habitat requirements of taxa in the form of ordinary differential equations. A detailed model description is provided in Text S1 (see also Schuwirth \& Reichert, 2013; Schuwirth et al., 2016; Kattwinkel et al., 2016). The growth, death, and respiration rates are formulated based on the basal metabolic rate which depends on temperature and body size according to the metabolic theory of ecology (Brown et al., 2004). The growth rates of the different invertebrate taxa depend on the availability of food and on habitat capacity, the latter of which depends on environmental conditions regarding microhabitats (substrate), current velocity, and maximum summer temperatures. Primary production depends on nutrients, temperature, and light. Feeding relationships are inferred from feeding types, body size and food availability (Schuwirth \& Reichert, 2013). So, biotic interactions explicitly accounted for are predation and (exploitative) competition for food. The consumption yields can take into account energy content and elemental composition of food sources. The death rates of invertebrates depend on water quality regarding organic matter leading to oxygen depletion 
(saprobic conditions) and organic micropollutants. Habitat requirements and tolerance to water quality impairment of the different taxa are derived from trait databases (Tachet et al., 2000; Liess \& von der Ohe, 2005; Schmidt-Kloiber \& Hering, 2015).

The model is not spatially explicit but it allows for the definition of different zones (habitats) within each modelled site that can differ regarding any of the environmental conditions that are used as model input. Here, we made use of this feature by differentiating between lentic and lotic zones, in accordance with the macroinvertebrate sampling (see below). Furthermore, within each zone, the areal fractions of different microhabitat/substrate types were specified. Depending on environmental conditions and the autecological traits of the taxa from the source pool, the model predicts the probability of observation for each tax on from equilibrium biomass following Schuwirth et al. (2016) (see Appendix S1 for a more detailed description and mathematical equations). Briefly, for each taxon, we first estimate the predicted number of individuals present on the sampled area by dividing the predicted population biomass density by the typical individual biomass of the taxon and by multiplication with the sampling area. We then calculate the probability of observing this taxon based on the expected number of individuals and accounting for observation errors: we assume a certain probability of catching and correctly identifying an individual that is present, a (relatively low) probability that individuals that were sampled are drifted from upstream instead of having a stable population at the site, and a certain probability that despite of having a stable population at the site the taxon is absent at the sampling site (e.g. due short-term disturbance or emergence).

\section{Study sites}

We studied the effect of restoration on macroinvertebrate communities in two Swiss rivers by comparing communities in lotic and lentic habitats of degraded (i.e. unrestored) and restored sections (Fig. 1). The degraded sections are representative for the condition of the restored sections before restoration. The rivers were selected from a dataset of European rivers (Hering et al., 2015), for their similarity in river type, their geographical proximity, and for sharing the same ecoregion. However, the Thur River is larger and has a higher discharge than the Töss River which can be reflected by differences in community composition between the rivers. Both rivers were channelized in the middle of the $19^{\text {th }}$ century to increase flood security and to gain agricultural land. Most of the natural river floodplains disappeared and the rivers were reduced to straight channels. Restoration aimed at improving the hydromorphological conditions by lowering the remaining floodplains and removing the embankments to provide more space for the rivers. The reaches studied at the Thur River consist of a restored section of $1.5 \mathrm{~km}$ in length (restoration date 2002) and an unrestored section situated $650 \mathrm{~m}$ upstream of the restored site. The sections at the Töss River consist of a shorter restored section of $0.2 \mathrm{~km}$ in length (restoration date 1999) and an unrestored section situated $350 \mathrm{~m}$ upstream. The Thur catchment consists of 59\% agricultural area and $33 \%$ forest and semi-natural areas, the Töss catchment of 36\% and 59\%, respectively. In both cases, no tributaries or changes in the chemical state occurred between the unrestored and restored sites. With this design of comparing unrestored and restored sections close to each other within the same river, the major factors expected to lead to differences between the biological communities of the sections in the same river are the morphological changes induced by restoration measures. Restoration had on one hand measurable positive effects on instream conditions, with a higher variability in the water depth, river width and flow velocity. The removal of the embankments along the Thur River increased the width variability of the river. In the Töss River, the creation of a secondary connected channel increased the variability of flow velocity and water depth. On the other hand restoration recreated gravel bars along the restored section of the rivers (Paillex et al., 2017). 
We measured several variables needed as model input at the study sites: the wetted area of the river, the current velocity, and the type and coverage of microhabitats. In addition, from existing data for each river and GIS analyses, we derived the maximum and average yearly water temperature, the concentrations of phosphorus, nitrogen, suspended organic matter in the water, and estimated the quantity of litter input and fraction of shading from the riparian zone, the water quality class corresponding to the saprobic system, and the level of organic micropollutants in the water column.

\section{Macroinvertebrates}

Macroinvertebrates were sampled in July 2012 with a multi-habitat sampling approach, reflecting the proportion of the microhabitat types that are present with more than $5 \%$ of coverage. Samplings were accomplished by positioning a kick-net (mesh size of $500 \mu \mathrm{m}$ ) and disturbing the substrate for a distance that equals the square of the frame width upstream of the net $(0.25 \mathrm{~m} \times 0.25 \mathrm{~m}) .20$ sample units were taken according to the share of microhabitats along a river section of $200 \mathrm{~m} .5$ additional sample units were taken in lentic zones (flow velocities $0-30 \mathrm{~cm} / \mathrm{s}$, water depth $1-30 \mathrm{~cm}$ ). Those two types of habitats were analysed separately as expectations are different in terms of macroinvertebrate communities between lotic and lentic zones. We quantified the compositional difference in the samples with a Correspondence Analysis (CoA, R package ade4, Dray \& Dufour, 2007). Communities were divided into the groups of EPT (Ephemeroptera, Plecoptera, Trichoptera) and $\mathrm{COH}$ (Coleoptera, Odonata, Heteroptera) species to highlight the effect of restoration on the main species groups inhabiting rivers and requiring different habitat conditions. Molluses and crustaceans were also grouped separately because many invasive species belong to these two groups (DAISIE, 2009).

To determine the source pool of taxa that can potentially colonize the study sites, we defined an area with a radius of $5 \mathrm{~km}$ around the restored sites from which macroinvertebrates can disperse to recolonize the restored sites (Fig. 1). A distance of 0-5 km from a site was assumed as a distance not limiting macroinvertebrates to disperse and colonize the site (Sundermann, Stoll \& Haase, 2011). Existing data on macroinvertebrates in these areas were compiled, and the resulting list formed the local pool of taxa (Table S1). In addition, we compiled data from literature on alien species already observed once in the Rhine catchment (Leuven et al., 2009), and they formed the regional pool of species which can potentially colonize the restored rivers in the future (Table S1). The Rhine River is situated downstream $(13-17 \mathrm{~km})$ of the restored sites studied and is regarded as a highway for the dispersal of alien and invasive freshwater species.

\section{Bayesian inference}

In order to quantify model uncertainty and to calibrate the parameters of the model, we applied Bayesian inference. With Bayesian inference we combined our prior knowledge (Table S2) about the parameters with the information from the observational data of all the study sites to derive a posterior parameter distribution (Ellison, 2004). We used the Markov chain Monte Carlo technique to generate a sample from the posterior parameter distribution, which allows us to estimate properties of this distribution, such as posterior means of the parameters, their variance-covariance matrix, or marginal probability densities of individual parameters (Gelman et al., 1995). To accelerate the process and check for convergence, we used 24 chains running in parallel with an overall sample size of 1'000'000 iterations. The prior and the posterior parameter samples were propagated through the model to calculate the prior and posterior probabilities of taxa occurrence at the study sites. To estimate the performance of both the uncalibrated and calibrated model, we compared their outputs with a 
random model where the presence/absence of each taxon at each site was assigned randomly with equal probability defined with a Bernoulli distribution.

\section{Scenarios}

In addition to modelling the communities at the four sites under the current environmental conditions (restored and unrestored sites at both rivers), we tested the effects of two scenarios on the occurrence of the macroinvertebrate taxa using the posterior parameter sample for the source pool taxa. 1: increasing spread of invasive species. We tested the effect of higher numbers of alien species arriving in the ecosystem on the native taxa. The alien species were selected among the observed species in the Rhine catchment (Leuven et al., 2009), and we calculated their probability to develop a population within the rivers depending on their autecological traits, the environmental conditions, and biotic interactions with the current community of mainly native taxa. We assumed that the alien species would jointly arrive at the sites, and according to their probability to establish a population, we assessed their influence on the native taxa. Native taxa were assumed to be affected if they were correctly predicted in the absence of alien species, and subsequently underestimated when alien species were included in the model. The intensity of the threat per native taxa was calculated as the number of habitat types (lotic and lentic in each river and site, i.e. unrestored and restored) not inhabited by this taxon in the presence of invasive species compared to the current number of observed habitat types inhabited by the native taxa. 2: changing water quality. To limit the threat of invasions on native taxa, one solution could be to improve the water quality and recreate physico-chemical conditions suitable for sensitive native taxa, while a deterioration of water quality and habitats could reduce the richness of native communities to a few tolerant species. We simulated the effect of changing water quality on the presence of native and alien taxa. We analyzed the effect of the water quality classes corresponding to saprobic conditions (organic matter that leads to a reduction in oxygen) on community richness (Rolauffs et al., 2004; Schuwirth \& Reichert, 2013; Schmidt-Kloiber \& Hering, 2015; Schuwirth et al., 2016). While the water quality class in the current state of the rivers corresponds to beta-meso-saprobic conditions, we tested the effect of the water quality ranging from worst case conditions with high level of organic pollution (i.e. low water quality corresponding to poly-saprobic conditions) to best case conditions without organic pollution (corresponding to xeno-saprobic conditions). In these scenarios, only the water quality was modified, assuming habitat conditions in the observed state. We compared the patterns of the taxa richness predicted within each site following the change of water quality.

\section{Results}

Seventy-six taxa exist at all sites combined with an average density of 2666 individuals $/ \mathrm{m}^{2}$. The study sites in the Töss River encompass 60 taxa $\left(2935\right.$ individuals $\left./ \mathrm{m}^{2}\right)$ and, in the Thur River, 52 taxa (2398 individuals $/ \mathrm{m}^{2}$ ). One alien species, Potamopyrgus antipodarum, is present in the Thur River with a density of 28 individuals $/ \mathrm{m}^{2}(1.2 \%$ of the total abundance), while no alien species were observed at the sites in the Töss River. The difference in community composition between the rivers is larger than the differences between restored and unrestored sites (Table S3). Restoration aimed to improve the habitat quality, but the difference between the rivers was still higher than restoration effects within the rivers (Table S3) partially explained by physical and morphological differences between rivers. Twentynine percent of the macroinvertebrate composition is explained along the first axis of the correspondence analysis, and 19.9\% along the second axis (Table S3). Restored sites within the Thur River encompass more taxa than unrestored sites (difference between restored and unrestored sites are 7 and 8 taxa in lentic and lotic habitats, respectively, Table 1). Restored sites within the Töss River are 1 to 2 taxa richer than unrestored sites. The EPT and the 
molluscs richness was higher in restored sites, while the $\mathrm{COH}$ richness remained stable (Table 1).

Table 1 Benthic invertebrate richness measured in the Thur and Töss Rivers in unrestored (left values) and restored (right values) sites. The richness is expressed as the total richness, the EPT and COH richness (EPT: Ephemeroptera + Plecoptera + Trichoptera, $\mathrm{COH}$ :

Coleoptera + Odonata + Heteroptera), and the richness of molluscs, crustaceans, diptera and alien species. The information is given for communities in the main river channel (i.e. lotic zone), and in more lentic environments along the river banks (i.e. lentic zone).

\begin{tabular}{llll}
\hline Richness & Sample & Thur & Töss \\
\hline Total & lotic & $20 ; 28$ & $26 ; 27$ \\
& lentic & $20 ; 27$ & $31 ; 33$ \\
EPT & lotic & $11 ; 13$ & $13 ; 12$ \\
& lentic & $6 ; 12$ & $8 ; 12$ \\
COH & lotic & $3 ; 3$ & $7 ; 6$ \\
& lentic & $4 ; 4$ & $10 ; 10$ \\
Molluscs & lotic & $0 ; 3$ & $1 ; 1$ \\
& lentic & $2 ; 3$ & $1 ; 2$ \\
Crustaceans & lotic & $1 ; 2$ & $0 ; 0$ \\
& lentic & $1 ; 2$ & $1 ; 1$ \\
Diptera & lotic & $4 ; 4$ & $3 ; 4$ \\
& lentic & $4 ; 3$ & $7 ; 5$ \\
Other taxa & lotic & $1 ; 3$ & $2 ; 4$ \\
& lentic & $3 ; 3$ & $4 ; 3$ \\
Alien & lotic & $0 ; 1$ & $0 ; 0$ \\
& lentic & $1 ; 1$ & $0 ; 0$ \\
\hline
\end{tabular}

\section{Performance of the mechanistic model without calibration}

For each taxon of the local taxa pool, we had one potential observation per site and habitat. This amounts to 468 presence/absence data points. For each taxon at each site and habitat we estimated the probability of occurrence with the model without calibration and by only propagating prior parameter uncertainty (Fig. S2). From the 212 observations of taxa in one of the habitats at one of the sites (="presence" data points), 140 had a mean predicted probability of occurrence larger than 0.5 in the corresponding habitat at the site, which is a fraction of $66 \%$, while $34 \%$ (i.e. 72 observations) were underestimated by the model (i.e. probability of occurrence below 0.5 ). From 256 of the taxa that were not observed in the habitats at the sites (="absence" data points), 165 had a mean predicted probability of occurrence below 0.5 , which is a fraction of $64 \%$, while $36 \%$ (i.e. 91 absent taxa) were overestimated by the model. The corresponding values at the mean of the prior distribution are provided in Table S4. The uncalibrated model has a slightly higher tendency toward overestimation. In the random model, the expected value for the predicted probability of occurrence of all taxa at all sites and habitats is $50 \%$. Therefore, the random model would on average predict 106 of the 212 observed taxa to occur and 128 of the 256 absent taxa to not occur.

\section{Calibration by Bayesian inference}

The marginal distributions of individual parameters were extracted from the joint prior and posterior parameter distributions (Fig. S1 Supporting Information). For some of the parameters, the posteriors were shifted and narrower (i.e. smaller range of values) compared 
to the priors, e.g. four parameters influencing the effect of environmental conditions (factor regarding current tolerance: $f_{\text {current intercept, }}$ saprobic conditions: $f_{\text {sapro intercept }}$, tolerance to pesticides: $f_{\text {orgmicropoll intercept }}$, microhabitat and substrate tolerance: $\left.f_{\text {microhab intercept }}\right)$ and most taxon specific modification factors of the growth rate $\left(f_{\text {gro tax }}\right)$ (Fig. S1). Differences between the prior and posterior distributions show that we can learn about these parameters from observations by inference (Fig. S1). For parameters showing no difference between prior and posterior distribution, we do not learn from the data. Such parameters are, for example, the half-saturation density parameter of biomass regarding self-inhibition $\left(h_{\text {dens }}\right.$, eqs, SI-13 and SI-14) or the half-saturation constant for the sum of food sources $\left(K_{\text {food }}\right.$, Fig. S1).

\section{Performance of the mechanistic model after Bayesian inference}

As expected, model performance improves with calibration by Bayesian inference. When propagating the posterior parameter distribution to the model results, from the 212 observations of taxa in one of the habitats at one of the sites (="presence" data points), 176 had a mean modelled probability of occurrence larger than 0.5 in the corresponding habitat and site, which is a fraction of $83 \%$, while $17 \%$ (i.e. 36 observed taxa) were underestimated by the model. From 256 of the taxa that were not observed in the habitats at the sites (="absence" data points), 216 had a mean probability of occurrence below 0.5 , which is a fraction of $84 \%$, while $16 \%$ (i.e. 40 absent taxa) were overestimated by the model. The model results at the maximum of the posterior distribution (the parameter set with the highest posterior density representing the best posterior point estimate of the parameters) are similar to the expected value (mean) when propagating the whole posterior distribution (see Table S4). These results illustrate the increasing goodness of fit due to model calibration, leading to a compliance of the model with observations for $84 \%$ of the taxa. The calibrated model has a low and comparable tendency of overestimation and underestimation. This is also true for the modelled richness of macroinvertebrate taxa (Fig. 2).

A

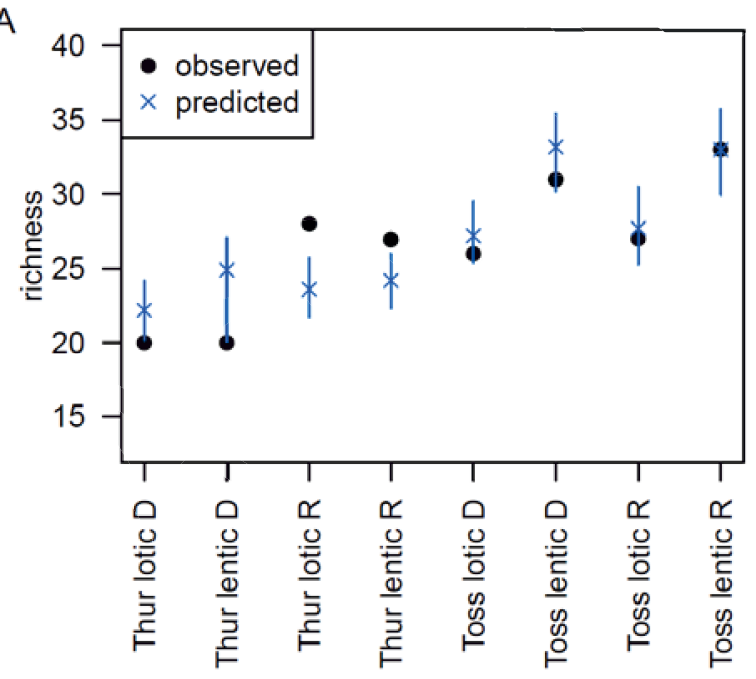

B

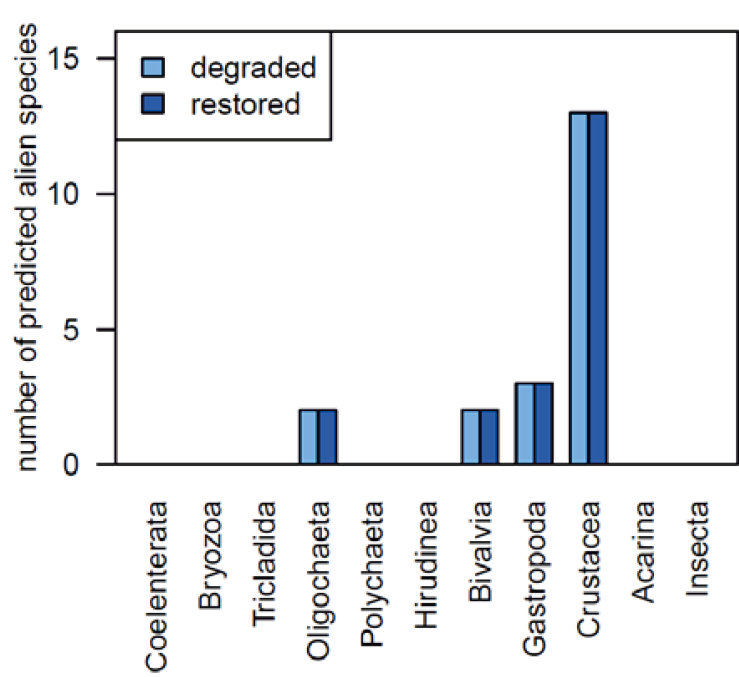

Fig. 2 Model outputs. (a) Predicted and observed richness in rivers and sites studied. Black dots represent the number of observed taxa within sites. Blue crosses represent the number of predicted taxa based on the maximum of the posterior, with a $90 \%$ probability interval. The information is given for communities in the main river channel (i.e. lotic zone), and in more lentic environments along the river banks (i.e. lentic zone). Degraded (unrestored) sites are labeled D, while restored sites are labeled R. (b) Predicted number of alien species in restored and unrestored sites according to the presence of observed native species and habitat conditions. Species are grouped according to their taxonomic order. 


\section{Identifying the missing taxa}

Among the local taxa pool, 26 taxa were supposed to colonize the habitats according to the calibrated model, but they were not observed. Among these 26 taxa, three were missing at the study sites of the Thur River while they were observed in the surroundings, Goera pilosa, Riolus sp., and Tabanidae (Table S5). Oppositely, the sites in the Töss River were already colonized by all the potential taxa found in the surroundings. The effect of seasonality on the emergence of G. pilosa and Tabanidae, as well as habitat conditions not yet taken into account in the model for Riolus sp. (i.e. preference for a siliceous instead of calcareous catchment geology), could explain why those taxa were missing at the study sites. The 23 other taxa were overestimated at some of the sites, while they were already observed at other sites in the same river. This could be due to model or sampling uncertainty. Seventeen taxa out of the 23 assumed to colonize the sites were insects and the six remaining taxa were hololimnic species (species with all life stages aquatic, see Table S5).

\section{Influence of scenarios on model outputs}

First, we investigated the potential effect of higher numbers of alien species arriving in the ecosystem on the native taxa. Using the calibrated model, we predicted that 20 alien species would establish a population in the studied rivers, among the 32 alien species present in the Rhine River. These include a high number of crustaceans (Fig. 2). The model predicted that restored and unrestored sites are equally invaded by alien species (Fig. 2). Twenty species were predicted to occupy both habitat types (i.e. lotic and lentic) at restored sites, while not all habitat types at the unrestored sites were predicted to be colonized ( 4 species were predicted to be absent of lentic habitats and 1 from lotic habitats). The same species are predicted to colonize the different sites within the rivers with a difference of one species between the rivers (Eriocheir sinensis is predicted to be absent from the Töss River, Table S6) and one species predicted to not colonize a restored site (Physella acuta, Table S6). Eighteen native taxa were predicted to be negatively affected by the presence of the alien species (Table 2). If the 20 alien taxa are incorporated into the community and 18 native taxa disappear, this will result in an increase in richness of 2 additional taxa compared to the current situation.

Second, we simulated the effect of changing water quality on the presence of native and alien taxa. From the current state of water quality (corresponding to beta-meso-saprobic conditions) towards better water quality (xeno-saprobic conditions), which indicates an improvement by two quality classes, the richness of native taxa is predicted to decrease (Fig. 3 ). This decrease is similar with the presence of alien species, but, under beta-meso-saprobic conditions, the community richness is expected to increase more than in any other condition (Fig. 3). Xeno-saprobic conditions are predicted to have a similar effect on macroinvertebrate richness than deterioration toward alpha-meso-saprobic conditions. However, a further deterioration of water quality is expected to have a negative effect on macroinvertebrate richness, which decreases to $<15$ taxa in the case of the worst water quality class (polysaprobic conditions, Fig. 3). 
Table 2 List of native taxa affected by alien species and the intensity of their threat. Affected taxa correspond to the taxa correctly predicted to occur in accordance with the observations, but becoming absent (i.e. underestimated by the model) when alien species are included in the model. The intensity of the threat per taxon corresponds to the ratio between the number of habitat types (lotic and lentic in each river and site, unrestored and restored) empty of the native taxon when alien species are included in the model compared to the observed number of habitat types inhabited by the taxon.

\begin{tabular}{ll}
\hline & \\
Affected taxa & Intensity \\
\hline Athericidae & 0.25 \\
Ecdyonurus sp. (Heptageniidae) & 0.50 \\
Baetis sp. (Baetidae) & 0.75 \\
Gammarus sp. (Gammaridae) & 0.75 \\
Simuliidae & 0.80 \\
Chironomidae & 1.0 \\
Elmis sp. (Elmidae) & 1.0 \\
Leptoceridae & 1.0 \\
Leuctra sp. (Leuctridae) & 1.0 \\
Limoniidae & 1.0 \\
Limnephilidae & 1.0 \\
Lumbriculidae & 1.0 \\
Oreodytes sp. (Dytiscidae) & 1.0 \\
Perla sp. (Perlidae) & 1.0 \\
Pisidium sp. (Sphaeriidae) & 1.0 \\
Platambus maculatus (Dytiscidae) & 1.0 \\
Psychodidae & 1.0 \\
Valvata cristata (Valvatidae) & 1.0 \\
\hline
\end{tabular}

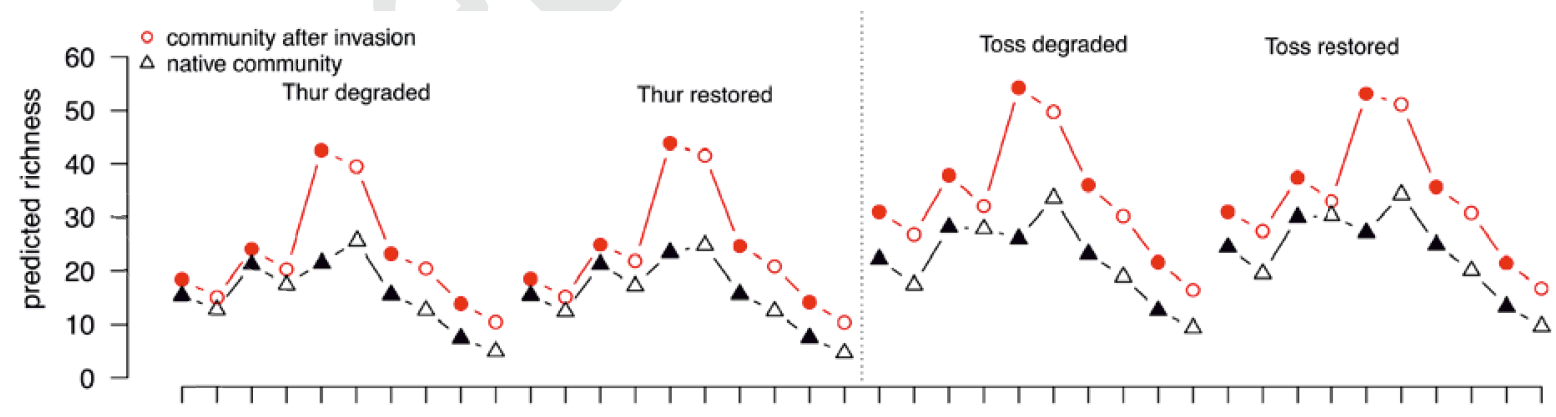

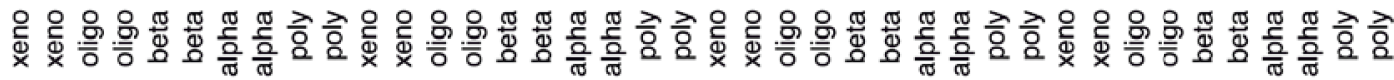

Fig. 3 Predicted change in community richness when water quality changes from xenosaprobic to poly-saprobic conditions along the x-axis. The current conditions in the Thur and Töss Rivers are beta-meso-saprobic. Number of predicted native taxa (black triangles) are compared to number of native and alien species after invasion (red dots) within each site studied. Filled symbols represent lotic conditions, while empty symbols represent lentic conditions. 


\section{Discussion}

\section{Importance of forecasting the effects of river restoration}

River restoration projects are increasing in number worldwide to reverse habitat degradation (Bernhardt et al., 2005). The benefits of these measures for aquatic invertebrates have often been less clearly shown than those for fish and terrestrial organisms (Hering et al., 2015). Knowledge about the consequences of restoring habitat conditions with respect to biodiversity is incomplete due to a lack of studies (Bernhardt et al., 2005). Restoration projects often fail to achieve their aim to restore biodiversity because the reasons for biodiversity loss have not been analyzed in detail and, consequently, the dominant determining variables may not have been systematically addressed (e.g. Paillex et al., 2009). In our study, the model showed a good ability to predict the presence of the observed taxa even before calibration (66\%). Bayesian inference improved the goodness of fit to $83 \%$. However, due to the high number of parameters and the complex shape of the posterior, the convergence of the Markov chains for the inference was slow, leading to a high computational burden ( 1 million simulations). Nevertheless, inference led to parameter adjustments and a considerable increase in the ability of the model to correctly describe the presence and absence of the taxa.

Concerning restoration, we expected that restoration would increase the diversity of habitat and physical conditions, leading to an increase in taxa richness (Lepori et al., 2005; Palmer, Menninger \& Bernhardt, 2010; Hering et al., 2015). This increase in community richness was partially reflected by the model and also observed in our data, which could be due to the measurable and positive effect of restoration on instream conditions, with higher variability in river depth, river width and flow velocity (Paillex et al., 2017). While an increase in richness was already observed, additional species from the local pool of taxa are expected to colonize the habitats. Possible reasons for their absence at the restored sites could be the effect of seasonality on emergence, unsuitable riparian habitat for insect adults which limits the development of aquatic populations, or biotic interactions within the community. These multiple reasons underlined the usefulness of a mechanistic model to provide information on the expected taxa at a site even if they have not yet been observed at the sites studied. In addition, such a model has the potential to predict the effects of restoration measures and to assess the level of success of a habitat transformation by comparing expectations with observations (Lamouroux et al., 2015; Castella et al., 2015).

\section{Predicting the effects of biological invasions post-restoration}

In addition to habitat destruction, native biodiversity is threatened by alien species (Chapin et al., 2000). We used the model to predict potential effects of changing the environmental conditions on the establishment of alien species present in the Rhine catchment. Within the same river, the model forecasted a similar use of the niche space in the restored and unrestored sites, with a slightly higher frequency of colonization of the restored sites. Recent empirical models predicted the richness and total abundance of alien species invasions after restoring connectivity in a large river floodplain (Paillex et al., 2015), and the increase of alien species was pronounced within the first few years after restoration. Evidence of recolonization by alien species was also reported after the restoration of the Rhine River (Simons et al., 2001), while for fishes Thomas et al. (2015) found no indication that alien species particularly benefited from river restorations in Europe. Alien macroinvertebrates may possess particular traits that facilitate their dispersal and their establishment in newly created habitats, such as long life, ovoviviparity and broad diet (Statzner, Bonada \& Dolédec, 
2008; Paillex et al., 2015). With the mechanistic model used in our study, we predicted which alien species could potentially develop a population at a site, and established a list of native taxa potentially affected by the presence of alien species, which is an improvement compared to empirical models that can't forecast the arrival of new invaders in the system. With a mechanistic model, the effect of the presence of alien species on native species in the food web can be estimated. Those native taxa that were predicted to occur without the presence of alien species, but were predicted to be absent in the presence of alien species, were further regarded as affected by the presence of alien species. In our study, we underlined that a high number of native taxa can be affected by the presence of alien species (i.e. 15 native taxa were predicted to be affected by the simulated presence of alien species within the study sites). These outcomes need to be validated as they are based on a limited number of traits that are not very accurately known. However, they provide an estimate of the level of threat to native species according to the transformation of habitats through restoration, and an estimate of the risk of invasive species establishing a population in those new sites. One potential solution to limit the threat to native species would be to improve the water quality and recreate physico-chemical conditions suitable for sensitive native taxa.

\section{Potential effects of improving or deteriorating water quality}

In addition to habitat destruction and biological invasions, deterioration of water quality is one of the reasons for decreases in species richness in streams (Sala et al., 2000). Aquatic macroinvertebrates are sensitive to enrichment in organic matter and subsequent decreases in oxygen. For this reason, we forecast the effect of improving the water quality on the occurrence of native and alien species. In the current situation (i.e. water quality corresponding to beta-meso-saprobic conditions) we predicted a potential increase in the presence of alien species from the River Rhine, if they overcome dispersal limitations. On the other hand, we showed that a deterioration of the water quality is expected to lead to a significant decrease in macroinvertebrate richness towards communities with fewer than fifteen taxa. The improvement in the water quality toward oligo- and xeno-saprobic conditions would lead to a lower predicted richness of macroinvertebrates, but to a lesser extent than a deterioration. Oligo- and xeno-saprobic conditions correspond to a very low level in organic matter which is a limiting factor for some species. However a low level of organic matter is expected to be favorable to more species than poly-saprobic conditions. The increase in alien species under beta-meso-saprobic conditions compared to native species highlights the needs of coordinated management of river morphology and water quality in order to limit the establishment of alien species in rivers in general and restored sites in particular. According to the results, both biological invasion and water quality impairment would have a strong negative effect on native richness. Efforts should be therefore made to maintain or even improve the good water quality when organic matter enrichment is high, and to restore habitat diversity and availability in order to increase the richness of native species in general. Overall, the predictions based on the mechanistic model and the observed communities are in accordance with the general expectations that streams are highly threatened by land-use, organic pollution and biotic exchange (Sala et al., 2000). These analyses represent a first attempt to develop scenarios for biodiversity management in highly threatened ecosystems. Those scenarios need to be refined and improved for policy-makers and to be quantitatively tested to reduce uncertainties about the outputs. Protecting biodiversity should lead to the mitigation of the pressures identified and further the development of management solutions.

\section{Model: towards a better mechanistic understanding}


The model is a step towards a better mechanistic understanding of the dependence of the invertebrate community on external influence factors and internal interactions. Combining theories (e.g. stoichiometry, food web theory, metabolic theory of ecology) with empirical data (i.e. trait databases) contributed to a successful first attempt to adequately describe the invertebrate communities. Bayesian inference allowed us to combine prior knowledge and information contained in the data to foster iterative learning about parameters and important mechanisms. Shifting taxon-specific factors to lower or higher values helped to increase goodness of fit during calibration, because these parameters directly influence the modelled probability of occurrence. However, the inference procedure had to find a compromise between matching observed presence or absence at the eight different habitat-site combinations, therefore perfect compliance with data can usually not be achieved by just modifying net growth rates. Unveiling the ecological reasons behind shifted posterior parameter distributions would be the next step to increase our mechanistic understanding and further improve the model.

The model is a simplified, mathematical expression of our current knowledge about the mechanisms leading to the coexistence of species in a community. As our knowledge is incomplete and simplifications are needed, there are opportunities for further improvement of the model regarding the model structure and the quantitative formulation of processes as well as in gathering and incorporating empirical data. As such improvements usually add more parameters to the model, it is important to assess the trade-off between the resulting increase in model complexity and improved model behavior. In particular, it would be interesting to investigate the potential benefit of (i) explicitly distinguishing different life stages of the organisms, (ii) better considering information about the resistance strategies of species towards disruptions (e.g. floods or droughts), (iii) including additional environmental influence factors (e.g. clogging of the river bed, additional water quality parameters like $\mathrm{pH} /$ alkalinity), (iv) different process parameterizations, and (v) gathering more detailed and consistent trait data than is currently available in trait data bases (e.g. regarding body size, food-sources of predators, temperature tolerance).

\section{Conclusions}

Predicting the taxonomic composition of invertebrate communities from the regional taxa pool and environmental conditions would be extremely useful to guide river management. However, due to the complexity of ecological systems, this is an overwhelmingly difficult task. Statistical approaches to do this have mainly been used in species distribution modelling and a need for better integration of ecological theory and concepts has been identified (Elith $\&$ Leathwick, 2009). We attempt to do so by describing the taxonomic composition of the invertebrate community in rivers by the mechanistic model "Streambugs" that combines elements of food-web models with the metabolic theory of ecology and known trait information of individual species. This model is applied to restored and unrestored sections of two rivers in Switzerland. Already the prior model predictions based exclusively on a parameterization of theoretical concepts and species-specific trait information, leads to predictions that are considerably better than those of a random model. Bayesian inference allowed us to learn from the observations about the values of model parameters and to further improve the model compliance with observations. Unfortunately, we did not have independent data sets for a more stringent model validation.

We applied the calibrated model to predict the potential effect of invasion of alien species and of changes in water quality. We (i) forecast a similar use of the habitats by alien species in the restored and unrestored sites with a slightly higher number of alien species at the restored sites, (ii) identified which alien species could potentially develop a population at 
restored and unrestored sites, and (iii) predicted that an improvement in the water quality would have a positive effect by limiting the number of alien species at the sites.

By demonstrating that the community composition can largely be described as a function of the most important external influence factors, we took a step towards predictive and mechanistic modelling of invertebrate communities according to habitat conditions. However, our results have to be interpreted with care: (i) As the comparison with a random model shows, some of the correspondences of model predictions with observations may just happen by chance, (ii) Bayesian inference may "misuse" some parameters to compensate for model structure deficits (e.g. missing processes), so that the compliance with observations becomes better for the wrong reason; (iii) the predictions of the effects of biological invasion and water quality changes are still somewhat speculative and need to be validated. Nevertheless, given the difficulty of the addressed task, our analyses demonstrated that our research direction is promising. We were quite successful in predicting the community composition based on mechanistic knowledge rather than just statistical correlation. In the coming years, many more river restoration projects will be undertaken in Switzerland and elsewhere. This offers the opportunity to generate more data to test the model, ideally following a before-after control-impact design. The application of the same procedure to many more sites could help (i) verifying or falsifying shifts in parameter distributions by Bayesian inference, (ii) extending the model to consider more mechanisms, (iii) further improving the predictive capability of the model. Thereby we would increase our understanding about community assembly of macroinvertebrates in streams and improve our ability to support river management decisions.

Acknowledgements We thank Tom Buijse and Daniel Hering for coordination of the Reform project and constant support, Reform partners for stimulating discussions, Benjamin Kupilas, Daniela Campana, Alexander Gieswein and Lisa Schülting for collecting field data, Rosi Siber for supporting GIS analyses, Pius Niederhauser, Patrick Steinmann, Andreas Hertig and Heinz Ehmann for providing data, and Andrew Clarke for language corrections. This paper results from the EU-funded Integrated Project REFORM (REstoring rivers FOR effective catchment Management), European Union's Seventh Programme for research, technological development and demonstration under Grant Agreement No. 282656.

\section{References}

Andersen T., Elser J.J. \& Hessen D.O. (2004) Stoichiometry and population dynamics. Ecology Letters, 7, 884-900.

Arce E., Archaimbault V., Mondy C.P. \& Usseglio-Polatera P. (2014) Recovery dynamics in invertebrate communities following water-quality improvement: taxonomy-vs trait-based assessment. Freshwater Science, 33, 1060-1073.

Bernhardt E.S., Palmer M.A., Allan J.D., Alexander G., Barnas K., Brooks S. et al. (2005) Synthesizing US river restoration efforts. Science, 308, 636-637.

Brown J.H., Gillooly J.F., Allen A.P., Savage V.M. \& West G.B. (2004) Toward a metabolic theory of ecology. Ecology, 85, 1771-1789.

Castella E., Beguin O., Besacier-Monbertrand A.L., Hug Peter D., Lamouroux N., Mayor Siméant H. et al. (2015) Realised and predicted changes in benthic invertebrate benthos after the restoration of connectivity of a large river. Freshwater Biology, 60, 1131-1146. 
Chapin F.S., Zavaleta E.S., Eviner V.T., Naylor R.L., Vitousek P.M., Reynolds H.L. et al. (2000) Consequences of changing biodiversity. Nature, 405, 234-242.

Daisie (2009) Handbook of alien species in Europe. In: Invading nature: springer series in invasion ecology. (Ed^ Eds J.A. Drake). Springer, Dordrecht, Netherlands

Dirzo R., Young H.S., Galetti M., Ceballos G., Isaac N.J.B. \& Collen B. (2014) Defaunation in the Anthropocene. Science, 345, 401-406.

Domisch S., Jahnig S.C., Simaika J.P., Kuemmerlen M. \& Stoll S. (2015) Application of species distribution models in stream ecosystems: the challenges of spatial and temporal scale, environmental predictors and species occurrence data. Fundamental and Applied Limnology, $186,45-61$.

Dray S. \& Dufour A.B. (2007) The ade4 package: implementing the duality diagram for ecologists. Journal of Statistical Software, 22, 1-20.

Elith J. \& Leathwick J.R. (2009) Species Distribution Models: Ecological Explanation and Prediction Across Space and Time. In: Annual Review of Ecology Evolution and Systematics. (Ed^Eds, pp. 677-697. Annual Review of Ecology Evolution and Systematics. Annual Reviews, Palo Alto.

Ellison A.M. (2004) Bayesian inference in ecology. Ecology Letters, 7, 509-520.

Floury M., Usseglio-Polatera P., Ferreol M., Delattre C. \& Souchon Y. (2013) Global climate change in large European rivers: long-term effects on macroinvertebrate communities and potential local confounding factors. Global Change Biology, 19, 1085-1099.

Gelman S., Carlin J.B., Stren H.S. \& Rubin D.B. (1995) Bayesian Data Analysis, Chapman and Hall, New York, USA.

Hering D., Aroviita J., Baattrup-Pedresen A., Brabec K., Buijse T., Ecke F. et al. (2015) Contrasting the roles of section length and instream habitat enhancement for river restoration sucess: $A$ field study on 20 European restoration projects. Journal of Applied Ecology, 52, 1518-1527.

Jahnig S.C., Brabec K., Buffagni A., Erba S., Lorenz A.W., Ofenbock T. et al. (2010) A comparative analysis of restoration measures and their effects on hydromorphology and benthic invertebrates in 26 central and southern European rivers. Journal of Applied Ecology, 47, 671-680.

Jones J.I., Murphy J.F., Collins A.L., Sear D.A., Naden P.S. \& Armitage P.D. (2012) The impact of fine sediment on macro-invertebrates. River Research and Applications, 28, 1055-1071.

Kattwinkel M., Reichert P., Rüegg J., Liess M. \& Schuwirth N. (2016) Modelling macroinvertebrate community dynamics in stream mesocosms contamined with a pesticide. Environmental Science and Technology, 50, 3165-3173.

Lamouroux N., Gore J.A., Lepori F. \& Statzner B. (2015) The ecological restoration of large rivers needs science-based, predictive tools meeting public expectations: an overview of the Rhône project. Freshwater Biology, 60, 1069-1084.

Lepori F., Palm D., Brannas E. \& Malmqvist B. (2005) Does restoration of structural heterogeneity in streams enhance fish and macroinvertebrate diversity? Ecological Applications, 15, 2060 2071.

Leps M., Tonkin J.D., Dahm V., Haase P. \& Sundermann A. (2015) Disentangling environmental drivers of benthic invertebrate assemblages: The role of spatial scale and riverscape heterogeneity in a multiple stressor environment. Science of the Total Environment, 536, 546-556.

Leuven R., Van Der Velde G., Baijens I., Snijders J., Van Der Zwart C., Lenders H.J.R. et al. (2009) The river Rhine: a global highway for dispersal of aquatic invasive species. Biological Invasions, 11, 1989-2008.

Liess M. \& Von Der Ohe P.C. (2005) Analyzing effects of pesticides on invertebrate communities in streams. Environmental Toxicology and Chemistry, 24, 954-965.

Merritt R.W. \& Cummins K.W. (1996) An introduction to the aquatic insects of North America, Kendall/Hunt, Dubuque, lowa. 
Moreno-Mateos D., Power M.E., Comin F.A. \& Yockteng R. (2012) Structural and Functional Loss in Restored Wetland Ecosystems. Plos Biology, 10, 1-8.

Paillex A., Castella E., Zu Ermgassen P. \& Aldridge D. (2015) Testing predictions of changes in alien and native macroinvertebrate communities and their interaction after the restoration of a large river floodplain (French Rhône). Freshwater Biology, 60, 1162-1175.

Paillex A., Dolédec S., Castella E. \& Mérigoux S. (2009) Large river floodplain restoration: predicting species richness and trait responses to the restoration of hydrological connectivity. Journal of Applied Ecology, 46, 250-258.

Paillex A., Schuwirth N., Lorenz A., Januschke K., Peter A. \& Reichert P. (2017) Integrating and extending ecological river assessment: Concept and test with two restoration projects. Ecological Indicators, 72, 131-141.

Palmer M.A., Menninger H.L. \& Bernhardt E. (2010) River restoration, habitat heterogeneity and biodiversity: a failure of theory or practice? Freshwater Biology, 55, 205-222.

Pereira H.M., Leadley P.W., Proenca V., Alkemade R., Scharlemann J.P.W., Fernandez-Manjarres J.F. et al. (2010) Scenarios for Global Biodiversity in the 21st Century. Science, 330, 1496-1501.

Poff N.L. (1997) Landscape filters and species traits: Towards mechanistic understanding and prediction in stream ecology. Journal of the North American Benthological Society, 16, 391 409.

Reichert P. \& Schuwirth N. (2010) A generic framework for deriving process stoichiometry in environmental models. Environmental Modelling \& Software, 25, 1241-1251.

Rolauffs P., Stubauer I., Zahradkova S., Brabec K. \& Moog O. (2004) Integration of the saprobic system into the European Union Water Framework Directive - Case studies in Austria, Germany and Czech Republic. Hydrobiologia, 516, 285-298.

Sala O.E., Chapin F.S., Armesto J.J., Berlow E., Bloomfield J., Dirzo R. et al. (2000) Global biodiversity scenarios for the year 2100. Science, 287, 1770-1774.

Schmidt-Kloiber A. \& Hering D. (2015) www.freshwaterecology.info - An online tool that unifies, standardises and codifies more than 20,000 European freshwater organisms and their ecological preferences. Ecological Indicators, 53, 271-282.

Schuwirth N., Dietzel A. \& Reichert P. (2016) The importance of biotic interactions for the prediction of macroinvertebrate communities under multiple stressors. Functional Ecology, 30, 974984.

Schuwirth N. \& Reichert P. (2013) Bridging the gap between theoretical ecology and real ecosystems: modeling invertebrate community composition in streams. Ecology, 94, 368-379.

Simons J., Bakker C., Schropp M.H.I., Jans L.H., Kok F.R. \& Grift R.E. (2001) Man-made secondary channels along the River Rhine (the Netherlands); results of post-project monitoring. Regulated Rivers-Research and Management, 17, 473-491.

Statzner B., Bonada N. \& Dolédec S. (2008) Biological attributes discriminating invasive from native European stream macroinvertebrates. Biological Invasions, 10, 517-530.

Strayer D.L. (2010) Alien species in fresh waters: ecological effects, interactions with other stressors, and prospects for the future. Freshwater Biology, 55, 152-174.

Sundermann A., Stoll S. \& Haase P. (2011) River restoration success depends on the species pool of the immediate surroundings. Ecological Applications, 21, 1962-1971.

Tachet H., Richoux P., Bournaud M. \& Usseglio-Polatera P. (2000) Invertébrés d'eau douce., Centre National de la Recherche Scientifique Editions, Paris.

Thomas G., Lorenz A.W., Sundermann A., Haase P., Peter A. \& Stoll S. (2015) Fish community responses and the temporal dynamics of recovery following river habitat restorations in Europe. Freshwater Science, 34, 975-990.

Tockner K. \& Stanford J.A. (2002) Riverine flood plains: present state and future trends. Environmental Conservation, 29, 308-330.

Townsend C.R. \& Hildrew A.G. (1994) Species traits in relation to a habitat templet for river systems. Freshwater Biology, 31, 265-275. 
Vorosmarty C.J., Mcintyre P.B., Gessner M.O., Dudgeon D., Prusevich A., Green P. et al. (2010) Global threats to human water security and river biodiversity. Nature, 467, 555-561.

\section{Supporting Information}

Additional supporting information may be found in the online version of this article:

Appendix S1. Additional information about the methods.

Appendix S2. Output of the simulation, list of overestimated, underestimated, correctly predicted and correctly not predicted taxa.

Table S1. Local and regional pool of species.

Table S2. Model parameters.

Table S3. Macroinvertebrate composition per site after a correspondence analysis.

Table S4. Model performance.

Table S5. List of native taxa overestimated by the model and their frequency of overestimation.

Table S6. Predicted invasive species per site.

Fig. S1. Marginals of the prior and the posterior parameter distribution.

Fig. S2. Probability of occurrence based on prior and posterior distribution.

Data S1. Observed abundance of macroinvertebrates per site in the Töss River.

Data S2. Observed abundance of macroinvertebrates per site in the Thur River.

Data S3. Environmental conditions for each study site. 
